\title{
Substâncias húmicas e ácido indolbutírico no enraizamento in vitro de mirtileiro
}

\section{'Woodard'}

\author{
Humic substances and indolebutyric acid in the in vitro rooting of 'Woodard' blueberry \\ Sustancias húmicas y ácido indolbutírico en el enraizamiento in vitro del arándano 'Woodard'
}

Recebido: 23/08/2021 | Revisado: 28/08/2021 | Aceito: 02/09/2021 | Publicado: 05/09/2021

Bruna Andressa dos Santos Oliveira
ORCID: https://orcid.org/0000-0003-0272-075X
Universidade Federal de Pelotas, Brasil
E-mail: brunah.andressa@gmail.com
Adriane Marinho de Assis
ORCID: https://orcid.org0000-0003-4230-1242
Universidade Federal de Pelotas, Brasil
E-mail: agroadri17@gmail.com
Patrícia Maciejewski
ORCID: https://orcid.org/0000-0003-0760-0861
Universidade Federal de Pelotas, Brasil
E-mail: agropatriciam@gmail.com
Aline Ramm
ORCID: https://orcid.org/0000-0002-5635-7776
Universidade Federal de Pelotas, Brasil
E-mail: alineramm45@gmail.com
Dianini Brum Frölech
ORCID: https://orcid.org/0000-0003-0080-1759
Universidade Federal de Pelotas, Brasil
E-mail: dianinifrolech.enologia@ gmail.com
Márcia Wulff Schuch
ORCID: https://orcid.org/0000-0001-5237-8302
Universidade Federal de Pelotas, Brasil
E-mail: marciaws@ ufpel.edu.br

\begin{abstract}
Resumo
O objetivo do trabalho foi avaliar o efeito da presença e ausência de ácido indolbutírico e concentrações de substâncias húmicas no enraizamento in vitro de mirtileiro 'Woodard'. O delineamento experimental foi o inteiramente casualizado, em esquema bifatorial $2 \times 3$, sendo os fatores: presença $\left(1 \mathrm{mg} \mathrm{L}^{-1}\right)$ ou ausência $\left(0 \mathrm{mg} \mathrm{L}^{-1}\right)$ de regulador de crescimento ácido indolbutírico (AIB) e concentrações de substâncias húmicas $(\mathrm{SH})$ (Solohumics $\left.{ }^{\circledR}\right)(0$; $\left.1 ; 2 ; 3 \mathrm{mg} \mathrm{L}^{-1}\right)$. Aos 60 dias avaliou-se: porcentagem de sobrevivência, comprimento da parte aérea, número de brotações, comprimento da maior brotação, porcentagem de enraizamento, número de raízes, comprimento da maior raiz, massa de matéria fresca e seca de parte aérea e raiz. Os resultados mostram que com exceção do tratamento sem o uso de SH e AIB, nos demais houve $100 \%$ de sobrevivência. O maior comprimento da parte aérea foi verificado sem o uso de AIB e com 3 mg L L ${ }^{-1}$ de $\mathrm{SH}$, bem como da maior brotação, raiz, número de raízes, da massa da matéria fresca da parte aérea e massa de matéria seca das raízes. O maior número de brotos foi observado sem o uso de AIB e com $2 \mathrm{mg} \mathrm{L}^{-1}$ de SH. Quanto ao enraizamento, sem o uso de AIB e SH não houve formação de raiz, diferindo das demais, que apresentaram $100 \%$ de enraizamento. A maior média da massa da matéria seca da parte aérea foi obtida com o uso de AIB e $3 \mathrm{mg} \mathrm{L}^{-1}$ de SH. Assim, concluiu-se que o enraizamento in vitro de mirtileiro 'Woodard' pode ser realizado com o uso de $3 \mathrm{mg} \mathrm{L}^{-1}$ de substâncias húmicas, sem o ácido indolbutírico.
\end{abstract}

Palavras-chave: Pequenas frutas; Vaccinium spp.; Biostimulantes.

\begin{abstract}
The objective of this work was to evaluate the effect of the presence and absence of indolebutyric acid and concentrations of humic substances on the in vitro rooting of 'Woodard' blueberry. The experimental design was completely randomized, in a $2 \times 3$ bifactorial scheme, with the following factors: presence $\left(1 \mathrm{mg} \mathrm{L}^{-1}\right)$ or absence $(0 \mathrm{mg}$ $\left.\mathrm{L}^{-1}\right)$ of indolebutyric acid (IBA) growth regulator and humic substances concentrations (SH) (Solohumics $\left.{ }^{\circledR}\right)(0 ; 1 ; 2 ; 3$ $\mathrm{mg} \mathrm{L}^{-1}$ ). At 60 days it was evaluated: survival percentage, shoot length, number of shoots, length of the largest shoot, percentage of rooting, number of roots, length of the largest root, fresh and dry matter weight of shoot and root. The results show that, with the exception of the treatment without the use of SH and AIB, in the others there was $100 \%$ survival. The longest shoot length was verified without the use of IBA and with $3 \mathrm{mg} \mathrm{L}^{-1}$ of SH, as well as the largest shoot, root, number of roots, shoot fresh matter mass and dry matter mass of the shoots. roots. The greatest number of
\end{abstract}


shoots was observed without the use of IBA and with $2 \mathrm{mg} \mathrm{L}^{-1}$ of SH. As for rooting, without the use of AIB and SH there was no root formation, differing from the others, which showed $100 \%$ rooting. The highest average of shoot dry matter mass was obtained with the use of IBA and $3 \mathrm{mg} \mathrm{L}^{-1}$ of SH. Thus, it was concluded that the in vitro rooting of 'Woodard' blueberry can be performed using $3 \mathrm{mg} \mathrm{L}^{-1}$ of humic substances, without indolebutyric acid.

Keywords: Small fruits; Vaccinium spp.; Biostimulants.

\section{Resumen}

El objetivo de este trabajo fue evaluar el efecto de la presencia y ausencia de ácido indolbutírico y concentraciones de sustancias húmicas sobre el enraizamiento in vitro del arándano 'Woodard'. El diseño experimental fue completamente aleatorizado, en un esquema bifactorial $2 \times 3$, con los siguientes factores: presencia $\left(1 \mathrm{mg} \mathrm{L}^{-1}\right)$ o ausencia $\left(0 \mathrm{mg} \mathrm{L}^{-1}\right)$ de ácido indolbutírico (IBA) regulador del crecimiento y concentraciones de sustancias húmicas (SH ) (Solohumics $\left.{ }^{\circledR}\right)(0$; 1; 2; $3 \mathrm{mg} \mathrm{L}^{-1}$ ). A los 60 días se evaluó: porcentaje de supervivencia, longitud de brote, número de brotes, longitud del brote más grande, porcentaje de enraizamiento, número de raíces, longitud de la raíz más grande, peso de materia fresca y seca de brote y raíz. Los resultados muestran que, a excepción del tratamiento sin uso de SH y AIB, en los demás hubo un $100 \%$ de supervivencia. Se verificó la mayor longitud de brote sin el uso de IBA y con $3 \mathrm{mg} \mathrm{L}^{-1} \mathrm{HS}_{\text {, }}$ así como el brote más grande, raíz, número de raíces, masa de materia fresca de brote y masa de materia seca de los brotes. El mayor número de brotes se observó sin el uso de IBA y con $2 \mathrm{mg} \mathrm{L}^{-1}$ de $\mathrm{SH}$. En cuanto al enraizamiento, sin el uso de AIB y SH no hubo formación de raíces, a diferencia de los demás, que mostraron un $100 \%$ de enraizamiento. El mayor promedio de masa de materia seca de brotes se obtuvo con el uso de IBA y $3 \mathrm{mg} \mathrm{L}^{-1} \mathrm{de} \mathrm{SH}^{-}$ Así, se concluyó que el enraizamiento in vitro del arándano 'Woodard' se puede realizar utilizando $3 \mathrm{mg} \mathrm{L}^{-1}$ de sustancias húmicas, sin ácido indolbutírico.

Palabras clave: Frutos pequeños; Vaccinium spp.; Bioestimulantes.

\section{Introdução}

A região Sul do Brasil possui grande potencial para a produção de pequenas frutas, principalmente o mirtilo (Vaccinium spp.) (Schuch \& Tomaz, 2019), sendo uma frutífera originária de algumas regiões da Europa e América do Norte, onde é muito apreciada por seu sabor exótico, pelo valor econômico e por suas propriedades medicinais, sendo considerada como "fonte de longevidade" (Rufato \& Antunes, 2016).

Para a produção de mudas de mirtileiro a micropropagação pode ser adotada, em função da eficiência em qualidade, quantidade, além do tempo de formação das mudas (Damiani \& Schuch, 2008). Porém, para o uso desse método de propagação tornar-se comercialmente viável na fruticultura e poder competir com os métodos tradicionais de propagação, tais como a estaquia, é necessário reduzir o custo de produção (Schuch \& Tomaz, 2019).

Os principais fatores que elevam o custo de produção na micropropagação estão ligados ao uso de determinados reagentes e equipamentos, além da contratação de mão de obra capacitada e estrutura de laboratórios específicos (Souza \& Junghans, 2006; Costa et al.; 2007). Dentre esses, as auxinas, substâncias com capacidade de promover o crescimento e a divisão celular em cultura de tecidos (Krikorian, 1991), têm sido utilizadas isoladamente ou em combinação no meio de enraizamento (Gattapaglia \& Machado, 1998), visando a estimulação de raízes adventícias (Taiz \& Zeiger, 2004).

Um dos tipos de auxina é o ácido indolbutírico (AIB) (Hartmann et al., 1997) que apesar de ser produzida por empresas especializadas, apresenta custo elevado (Baldotto \& Baldotto, 2014).

Em função desses aspectos, visando reduzir o período de desenvolvimento da muda e, consequentemente, os custos de produção, algumas alternativas inovadoras podem ser adotadas, como o uso de substâncias húmicas. Constituídas pelas frações ácidos húmicos, ácidos fúlvicos e huminas, estas exercem efeitos estimulantes na parte aérea, como incrementos do acúmulo de nutrientes foliares, síntese de clorofilas e atuam no enraizamento de várias plantas de interesse agronômico (Baldotto et al., 2009; Baldotto \& Baldotto, 2014), ou seja, influenciam no crescimento de raízes de forma semelhante à promovida pela auxina, pois ativam a bomba de prótons $(\mathrm{H}+)$, da plasmalema e do vacúolo dentro da rota de biossíntese da auxina (Elena et al., 2009; Trevisan et al., 2011).

Com relação aos ácidos húmicos, esses possuem aspectos econômicos e ambientais vantajosos em relação ao ácido indolbutírico (Loss et al., 2009; Pizzatto et al., 2011). Além disso, são fontes naturais renováveis, pois podem ser extraídos de 
resíduos urbanos, como lodo de lixo e esgoto (Canellas et al., 2000), bem como da agricultura, através de resíduos do processamento de frutos, esterco de animais, entre outros (Melo et al., 2008).

Alguns trabalhos com enraizamento in vitro foram realizados em algumas frutíferas como: morangueiro (RzepkaPlevnes et al., 2011), macieira (Baraldi et al., 1991) e kiwizeiro (Marino et al., 2008). Entretanto, a resposta das plantas aos ácidos húmicos não é uniforme e varia de acordo com o genótipo, a matéria-prima em que esses compostos são extraídos e a concentração (Baldotto et al., 2011, 2012).

Como são escassas as publicações sobre o uso de substâncias húmicas na micropropagação de espécies frutíferas e não existem informações sobre a combinação da utilização dessas substâncias com auxinas na micropropagação de mirtileiro 'Woodard', objetivou-se avaliar o efeito da presença e ausência de ácido indolbutírico e concentrações de substâncias húmicas no enraizamento in vitro da referida cultivar.

\section{Metodologia}

O experimento foi realizado no período de maio a julho de 2019, no Laboratório de Propagação de Plantas Frutíferas, pertencente ao Departamento de Fitotecnia da Faculdade de Agronomia Eliseu Maciel-UFPel, localizada no município de Capão do Leão-RS.

O delineamento experimental foi o inteiramente casualizado, em esquema bifatorial 2x3, sendo os fatores: presença (1 $\left.\mathrm{mg} \mathrm{L}{ }^{-1}\right)$ ou ausência $\left(0 \mathrm{mg} \mathrm{L}^{-1}\right)$ de regulador de crescimento ácido indolbutírico (AIB) e concentrações de substâncias húmicas $\left(\right.$ Solohumics $\left.^{\circledR}\right)\left(0 ; 1 ; 2 ; 3 \mathrm{mg} \mathrm{L}^{-1}\right)$, totalizando oito tratamentos com cinco repetições, sendo utilizados cinco explantes para cada repetição.

O Solohumics ${ }^{\circledR}$ é um produto comercial composto por: ácido húmico (25\%), ácido fúlvico (5\%), matéria orgânica (59\%), carbono orgânico total (31\%) e potássio (3\%).

Os explantes retirados da parte mediana de plantas cultivadas in vitro foram cultivados em meio WPM (Wood Plant Media - Loyd \& McCown, 1980), contendo 0,1 $\mathrm{g} \mathrm{L}^{-1}$ de mio-inositol, $30 \mathrm{~g} \mathrm{~L}^{-1}$ de sacarose, $6 \mathrm{~g} \mathrm{~L}^{-1}$ de ágar; adicionado AIB e concentrações de substâncias húmicas, conforme o tratamento. $\mathrm{O}$ pH foi ajustado para 5,0 em peagâmetro Quimis ${ }^{\circledR} \mathrm{e}$, posteriormente, foram distribuídos $30 \mathrm{~mL}$ do meio em frascos de vidro com capacidade de $250 \mathrm{~mL}$. Logo após, realizou-se a autoclavagem em equipamento (autoclave) vertical Phoenix Luterco ${ }^{\circledR}$ a $120^{\circ} \mathrm{C}$ e 1,5 atm de pressão por 20 minutos.

Posteriormente, foi realizada a transferência dos explantes para os frascos em câmara de fluxo laminar, e os mesmos foram vedados com papel alumínio e filme plástico transparente e mantidos em sala de crescimento com fotoperíodo de 16 horas, temperatura de $25 \pm 2^{\circ} \mathrm{C}$ e intensidade luminosa de $27 \mu \mathrm{mol} \mathrm{m} \mathrm{m}^{-2} \mathrm{~s}^{-1}$.

Após 60 dias as variáveis avaliadas foram: porcentagem de sobrevivência, comprimento da parte aérea $(\mathrm{cm})$, número de brotações, comprimento da maior brotação $(\mathrm{cm})$, porcentagem de enraizamento (\%), número de raízes, comprimento da maior raiz $(\mathrm{cm})$, massa de matéria fresca e seca de parte aérea e raiz $(\mathrm{g})$.

Foi utilizada régua graduada para as mensurações de comprimento e balança analítica Bioprecisa ${ }^{\circledR}$ para aferir a massa de matéria fresca e seca da parte aérea e das raízes. Para a obtenção da massa de matéria seca o material foi colocado em estufa Quimis ${ }^{\circledR}$ com ventilação forçada a $50^{\circ} \mathrm{C}$, até a obtenção de peso constante.

Os dados foram submetidos à análise de variância através do teste $\mathrm{F}(\mathrm{p} \leq 0,05)$. Constatando-se significância estatística, as médias dos efeitos da presença ou ausência de AIB foram comparados pelo teste $t(p \leq 0,05)$ e as concentrações de substâncias húmicas pelo teste de Scott-Knott ( $\mathrm{p} \leq 0,05)$. 


\section{Resultados e Discussão}

Para as variáveis de sobrevivência e comprimento da parte aérea observou-se efeito significativo para os fatores de estudo (Tabela 1).

Tabela 1. Sobrevivência $(\%)$, comprimento da parte aérea $(\mathrm{cm})$, número de brotos e comprimento da maior brotação de mirtileiro 'Woodard' enraizadas in vitro, em função do uso de regulador de crescimento ácido indolbutírico (AIB) e das concentrações de substâncias húmicas.

\begin{tabular}{|c|c|c|c|c|}
\hline \multirow{3}{*}{$\begin{array}{l}\text { Regulador de } \\
\text { crescimento } \\
\text { (AIB) }\end{array}$} & \multicolumn{4}{|c|}{ Concentrações de substâncias húmicas $\left(\mathrm{mg} \mathrm{L}^{-1}\right)$} \\
\hline & 0 & 1 & 2 & 3 \\
\hline & \multicolumn{4}{|c|}{ Sobrevivência } \\
\hline Com & $100 \mathrm{aA}^{\mathrm{1} /}$ & $100 \mathrm{aA}$ & $100 \mathrm{aA}$ & $100 \mathrm{aA}$ \\
\hline \multirow[t]{2}{*}{ Sem } & $63 \mathrm{bB}$ & $100 \mathrm{aA}$ & $100 \mathrm{aA}$ & $100 \mathrm{aA}$ \\
\hline & \multicolumn{4}{|c|}{ Comprimento da parte aérea $(\mathrm{cm})$} \\
\hline Com & $2,32 \mathrm{aB}$ & $2,46 \mathrm{bB}$ & $2,71 \mathrm{bB}$ & $6,30 \mathrm{aA}$ \\
\hline \multirow[t]{2}{*}{ Sem } & $3,54 \mathrm{aB}$ & $6,12 \mathrm{aA}$ & $6,63 \mathrm{aA}$ & $7,07 \mathrm{aA}$ \\
\hline & \multicolumn{4}{|c|}{ Número de brotos } \\
\hline Com & $1,14 \mathrm{bB}^{1 /}$ & $1,41 \mathrm{bB}$ & $2,16 \mathrm{bA}$ & 3,16 aA \\
\hline \multirow[t]{2}{*}{ Sem } & $3,28 \mathrm{aA}$ & $2,86 \mathrm{aA}$ & $4,24 \mathrm{aA}$ & $3,62 \mathrm{aA}$ \\
\hline & \multicolumn{4}{|c|}{ Comprimento da maior brotação } \\
\hline Com & $1,76 \mathrm{aA}$ & $0,68 \mathrm{bB}$ & $1,46 \mathrm{aA}$ & $2,65 \mathrm{aA}$ \\
\hline Sem & $1,38 \mathrm{aA}$ & $1,49 \mathrm{aA}$ & $1,37 \mathrm{aA}$ & $2,67 \mathrm{aA}$ \\
\hline
\end{tabular}

1 Médias acompanhadas por mesma letra minúscula na coluna não diferem entre si pelo teste $\mathrm{t}$ $(\mathrm{p} \leq 0,05)$ comparando o uso de AIB e maiúscula na linha não diferem entre si pelo teste de ScottKnott $(\mathrm{p} \leq 0,05)$ comparando as concentrações de SH.

Fonte: Bruna Andressa dos Santos Oliveira.

Com relação à sobrevivência, com exceção do tratamento sem o uso de substâncias húmicas e de AIB, onde a sobrevivência foi de $63 \%$, nos demais tratamentos obteve-se $100 \%$ de sobrevivência (Tabela 1).

Em trabalho realizado por Cruz (2017) sobre o enraizamento in vitro de mirtileiro 'Woodard', a autora verificou $100 \%$ de sobrevivência, quando utilizado $0,5 \mathrm{mg} \mathrm{L}^{-1}$ de AIB no meio de cultura. Conforme Ristow et al. (2009), o mirtileiro apresenta lento desenvolvimento e baixo índice de sobrevivência das mudas após a formação das raízes.

Considerando que a sobrevivência está diretamente relacionada com o retorno do capital investido, a ocorrência de perdas de mudas poderá resultar em menor lucro ao produtor.

Para o comprimento da parte aérea, comparando o uso ou não de AIB em relação as concentrações de substâncias húmicas, constatou-se diferença significativa apenas com 1 e $2 \mathrm{mg} \mathrm{L}^{-1}$ de substâncias húmicas, em que as maiores médias foram verificadas no tratamento sem o uso de AIB. Porém, quando comparadas as concentrações de substâncias húmicas em

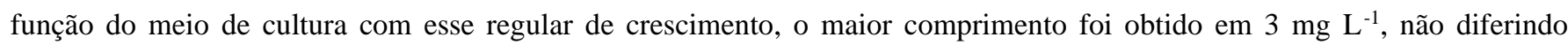
estatisticamente das concentrações 1 e $2 \mathrm{mg} \mathrm{L}^{-1}$ para o tratamento sem AIB. Por outro lado, com o uso de AIB a maior média foi observada na concentração de $3 \mathrm{mg} \mathrm{L}^{-1}$, diferindo estatisticamente das demais (Tabela 1).

Camargo (2015), observou que mirtileiro oriundo de micropropagação apresentou maior crescimento vegetativo inicial, representado pela maior altura de planta, quando comparado à estaquia. No caso de outras frutíferas, como a bananeira 
(Musa spp.) 'Preciosa', Costa et al. (2008) notaram maior comprimento de parte aérea quando o ácido indolbutírico foi adicionado no meio de cultura MS (Murashige \& Skoog, 1962).

Quanto ao número de brotos, quando comparado o meio de cultura com ou sem o uso de AIB nas diferentes concentrações de substâncias húmicas, observou-se as maiores médias para os tratamentos sem o uso de AIB, independente da concentração de substâncias húmicas, exceto para o tratamento com a concentração $3 \mathrm{mg} \mathrm{L}^{-1}$ dessas substâncias, em que não diferiu do tratamento com AIB (Tabela 1).

Em relação à concentração de substâncias húmicas comparada com ou sem o uso da referida auxina, $2 \mathrm{mg} \mathrm{L}^{-1}$ propiciou maior número brotos no tratamento sem AIB, não diferindo estatisticamente das demais concentrações. No entanto, com adição de AIB, mais brotos foram registrados com $3 \mathrm{mg} \mathrm{L}^{-1}$ de substâncias húmicas, não diferindo do tratamento onde utilizou-se $2 \mathrm{mg} \mathrm{L}^{-1}$ de tais substâncias (Tabela 1).

O maior número de brotos poderá contribuir com a taxa fotossintética das mudas na aclimatização, que é considerada uma das etapas mais críticas da micropropagação. Além disso, Rodrigues et al. (2018) descreveram que o número de brotos é fundamental para garantir um bom desempenho das mudas, principalmente na fase posterior à aclimatização. Bowling (2000) também salienta a importância dessa variável, visto que brotação e florescimento deficientes podem ocasionar redução na produção de frutos.

Para o comprimento da maior brotação, quando comparado o meio de cultura com ou sem AIB em relação as concentrações de substâncias húmicas, apenas ocorreu diferença estatística com $1 \mathrm{mg} \mathrm{L}^{-1}$, sendo que naquelas mudas oriundas de cultivo in vitro sem o uso de AIB foi verificado a maior média. Em contrapartida, analisando apenas as concentrações de substâncias húmicas em relação ao meio de cultura com ou sem AIB, o meio de cultura com $3 \mathrm{mg} \mathrm{L}^{-1}$ de substâncias húmicas sem o uso de AIB resultou em maior comprimento, não diferindo das demais concentrações dessas substâncias (Tabela 1).

No presente estudo, quando aplicado $3 \mathrm{mg} \mathrm{L}^{-1}$ de substância húmica e com a presença de AIB, os resultados foram superiores aos descritos por Cruz (2017), que avaliando o efeito da presença ou ausência do uso de AIB no enraizamento in vitro de mirtileiro 'Woodard' verificou que o maior comprimento de brotação $(2,39 \mathrm{~cm})$ foi obtido com $0,5 \mathrm{mg} \mathrm{L}^{-1}$ de AIB em meio de cultivo WPM. Segundo Silva et al. (2003), o comprimento da brotação é determinado pelo fator genético, pela concentração do regulador de crescimento e o tipo de meio de cultura.

Nas avaliações referentes ao enraizamento, número de raízes e comprimento da maior raiz, ocorreu interação entre o meio de cultura com ou sem AIB e as concentrações de substâncias húmicas (Tabela 2). 
Tabela 2. Enraizamento (\%), número de raízes e comprimento da maior raiz (cm) de mirtileiro 'Woodard' enraizadas in vitro, em função do uso de regulador de crescimento ácido indolbutírico (AIB) e das concentrações de substâncias húmicas.

\begin{tabular}{ccccc}
\hline $\begin{array}{c}\text { Regulador de } \\
\text { crescimento } \\
(\text { AIB })\end{array}$ & \multicolumn{4}{c}{ Concentrações de substâncias húmicas $\left(\mathrm{mg} \mathrm{L}^{-1}\right)$} \\
\cline { 2 - 4 } & 0 & 1 & 2 & 3 \\
\cline { 2 - 4 } Com & $100 \mathrm{aA}^{\underline{1} /}$ & $100 \mathrm{aA}$ & $100 \mathrm{aA}$ & $100 \mathrm{aA}$ \\
Sem & $0 \mathrm{bB}$ & $100 \mathrm{aA}$ & $100 \mathrm{aA}$ & $100 \mathrm{aA}$ \\
\hline Com & $1,74 \mathrm{aB}$ & $3,07 \mathrm{bB}$ & $2,40 \mathrm{bB}$ & $5,34 \mathrm{aA}$ \\
Sem & $0 \mathrm{bB}$ & $4,90 \mathrm{aA}$ & $4,72 \mathrm{aA}$ & $5,36 \mathrm{aA}$ \\
\hline Com & $0,76 \mathrm{aB}$ & $1,06 \mathrm{aA}$ & $1,36 \mathrm{aA}$ & $1,42 \mathrm{aA}$ \\
Sem & $0 \mathrm{bB}$ & $1,46 \mathrm{aA}$ & $1,29 \mathrm{aA}$ & $1,74 \mathrm{aA}$ \\
\hline
\end{tabular}

1/ Médias acompanhadas por mesma letra minúscula na coluna não diferem entre si pelo teste $\mathrm{t}$ $(\mathrm{p} \leq 0,05)$ comparando o uso de AIB e maiúscula na linha não diferem entre si pelo teste de ScottKnott $(\mathrm{p} \leq 0,05)$ comparando as concentrações de $\mathrm{SH}$.

Fonte: Bruna Andressa dos Santos Oliveira.

Analisando o enraizamento, no tratamento sem AIB e substâncias húmicas não houve formação de raiz, diferindo dos demais, que apresentaram 100\% de enraizamento (Tabela 2).

Tahiri et al. (2016), avaliando a influência de substâncias húmicas no desenvolvimento do sistema radicular in vitro de duas espécies lenhosas, vidoeiro de prata (Betula pendula Roth) e amieiro preto (Alnus glutinosa L. Gaertn), observaram enraizamento entre 95 e 100\%. Em outro estudo, Baraldi et al. (1991) verificaram 96\% de enraizamento in vitro em maçã 'Golden delicious', quando foi adicionado no meio de cultura humato de potássio na concentração de $500 \mathrm{mg} \mathrm{L}^{-1}$ e 0 ou 0,06 $\mathrm{mg} \mathrm{L}^{-1}$ de AIB.

Segundo Damiani e Schuch (2009) o desenvolvimento de um sistema de enraizamento mais eficiente resulta em mudas com maior qualidade fisiológica e diminuição de perdas durante a fase de aclimatização. Kramer e Kozlowski (1972) citam que o enraizamento pode sofrer interferência de vários fatores, entre eles destacam-se: estado nutricional das plantas, época do ano, taxa de respiração e fotossíntese, bem como a relação carbono/nitrogênio.

Comparando os meios de cultura, a adição de $3 \mathrm{mg} \mathrm{L}^{-1}$ de substâncias húmicas no meio sem o uso de AIB proporcionou maior número de raízes, não diferindo estatisticamente do meio com AIB para a mesma concentração de substâncias húmicas. No entanto, no tratamento sem substâncias húmicas a maior média foi obtida com o uso de AIB, enquanto nos recipientes com 1 e $2 \mathrm{mg} \mathrm{L}^{-1}$ de substâncias húmicas a maior quantidade de raízes foi observado na ausência de AIB (Tabela 2).

Para a produção de mudas em escala comercial a emissão de raízes em maior número e comprimento é fator preponderante na constituição dos pomares, pois o sistema radicular bem formado favorece a absorção de nutrientes e água, propiciando, desta forma, um melhor desenvolvimento das mudas no campo (Fracaro, 2004; Zietemann \& Roberto, 2007; Carvalho Junior et al., 2009)

Rzepka-Plevnes et al. (2011), testando os efeitos de ácido húmico, AIB e ácido naftaleno acético (ANA) no enraizamento in vitro de duas cultivares de morangueiro 'Elsanta' e 'Senga Sengana', obtiveram maior número de raízes nas plantas cultivadas no meio com $1,0 \mathrm{mg} \mathrm{dm}^{-3}$ de AIB. Em relação ao uso de ácido húmico, a maioria das raízes da cultivar 
Elsanta foram observadas no meio com $1,0 \mathrm{mg} \mathrm{dm}^{-3}$ de ácido húmico oriundo de solo podzólico e para 'Senga Sengana,' com $5,0 \mathrm{mg} \mathrm{dm}^{-3}$ de ácido húmico proveniente de solo enferrujado.

No cultivo in vitro de maçã 'Golden delicious', houve aumento no número de raízes com a associação do regulador de crescimento AIB (sem e com 0,06 $\mathrm{mg} \mathrm{L}^{-1}$ ) com 250 e $500 \mathrm{mg} \mathrm{L}^{-1}$ de humato de potássio (BARALDI et al.,1991),

Com relação ao comprimento da maior raiz, comparando o meio de cultura com ou sem o uso de AIB em relação as concentrações de substâncias húmicas, o maior comprimento da raiz foi obtido no meio de cultura sem o uso de AIB e com 3 $\mathrm{mgL}^{-1}$ de substâncias húmicas, não diferindo estatisticamente do tratamento com o uso de AIB (Tabela 2). Em se tratando das concentrações de substâncias húmicas para cada meio de cultura com ou sem o uso de AIB, a maior média foi obtida com a 3 $\mathrm{mgL}^{-1}$ de substâncias húmicas, mas não diferiu estatisticamente das concentrações de 1 e $2 \mathrm{mg} \mathrm{L}^{-1}$, com ou sem o uso de AIB (Tabela 2).

Rzepka-Plevnes et al. (2011) observaram que a adição de ácido naftaleno acético no meio de cultura propiciou raízes mais longas em morangueiro (Fragaria $x$ ananassa Duch.) cultivado in vitro. Ao utilizar ácidos húmicos, esses autores verificaram as maiores raízes $(13,80 \mathrm{~cm})$ de 'Elsanta' na concentração de $5 \mathrm{mg} \mathrm{dm}^{-3} \mathrm{e}$, em 'Senga Sengana', as maiores raízes $(19,70 \mathrm{~cm})$ foram observadas com 1,0 $\mathrm{mg} \mathrm{dm}^{-3}$, ambas oriundas de solo podzólico.

De acordo com Vaughan e Malcolm (1985), este resultado pode estar relacionado ao forte estímulo das substâncias húmicas sobre o desenvolvimento radicular com concentrações relativamente pequenas de materiais húmicos em solução. Além de que, estas substâncias proporcionam a estimulação do alongamento radicular, pelos radiculares e produção radicular lateral (Zandonadi et al. 2007; Canellas et al. 2002; 2009).

Quanto a massa de matéria fresca e seca da parte aérea e massa seca das raízes, ocorreu interação entre o meio de cultura com ou sem o uso do regulador de crescimento AIB e as diferentes concentrações de substâncias húmicas. A massa da matéria fresca da parte aérea foi maior no tratamento sem o uso de AIB; entretanto, não diferiu estatisticamente do tratamento com o uso de AIB nas concentrações 2 e $3 \mathrm{mg} \mathrm{L}^{-1}$ (Tabela 3). 
Tabela 3. Massa matéria fresca da parte aérea, massa matéria fresca das raízes, massa matéria seca da parte aérea e das raízes (g) de mirtileiro 'Woodard' enraizadas in vitro, em função do uso de regulador de crescimento ácido indolbutírico (AIB) e das concentrações de substâncias húmicas.

\begin{tabular}{|c|c|c|c|c|}
\hline \multirow{3}{*}{$\begin{array}{l}\text { Regulador de } \\
\text { crescimento } \\
\text { (AIB) }\end{array}$} & \multicolumn{4}{|c|}{ Concentrações de substâncias húmicas $\left(\mathrm{mg} \mathrm{L}^{-1}\right)$} \\
\hline & 0 & 1 & 2 & 3 \\
\hline & \multicolumn{4}{|c|}{ Massa matéria fresca da parte aérea $(\mathrm{g})$} \\
\hline Com & $0,41 \mathrm{bB}^{\underline{1 /}}$ & $0,34 \mathrm{bB}$ & $0,50 \mathrm{aA}$ & $0,61 \mathrm{aA}$ \\
\hline \multirow[t]{2}{*}{ Sem } & $0,76 \mathrm{aA}$ & $0,73 \mathrm{aA}$ & $0,56 \mathrm{aA}$ & $1,09 \mathrm{aA}$ \\
\hline & \multicolumn{4}{|c|}{ Massa matéria fresca das raízes $(\mathrm{g})$} \\
\hline Com & $0,10^{\mathrm{NS}}$ & 0,10 & 0,05 & 0,07 \\
\hline \multirow[t]{2}{*}{ Sem } & 0,08 & 0,13 & 0,10 & 0,22 \\
\hline & \multicolumn{4}{|c|}{ Massa matéria seca da parte aérea (g) } \\
\hline Com & $0,01 \mathrm{aB}$ & $0,01 \mathrm{bB}$ & $0,01 \mathrm{bB}$ & $0,09 \mathrm{aA}$ \\
\hline \multirow[t]{2}{*}{ Sem } & $0 \mathrm{bB}$ & $0,05 \mathrm{aA}$ & $0,05 \mathrm{aA}$ & $0,08 \mathrm{aA}$ \\
\hline & \multicolumn{4}{|c|}{ Massa matéria seca das raízes (g) } \\
\hline Com & $0,021 \mathrm{aB}$ & $0,0041 \mathrm{bB}$ & $0,0034 \mathrm{bB}$ & $0,0126 \mathrm{aA}$ \\
\hline Sem & $0 \mathrm{bB}$ & $0,0075 \mathrm{aA}$ & $0,0074 \mathrm{aA}$ & $0,0128 \mathrm{aA}$ \\
\hline
\end{tabular}

1/ Médias acompanhadas por mesma letra minúscula na coluna não diferem entre si pelo teste $\mathrm{t}$ $(\mathrm{p} \leq 0,05)$ comparando o uso de AIB e maiúscula na linha não diferem entre si pelo teste de ScottKnott $(\mathrm{p} \leq 0,05)$ comparando as concentrações de SH. NS: não significativo.

Fonte: Bruna Andressa dos Santos Oliveira.

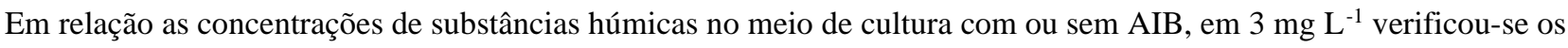
maiores valores de massa de matéria fresca para ambos os tratamentos, mas não houve diferença estatística em comparação ao meio de cultura em que foi usado $2 \mathrm{mg} \mathrm{L}^{-1}$ de substâncias húmicas e AIB, tampouco aos tratamentos com 0,1 e 2 mg $\mathrm{L}^{-1}$ de tais substâncias e sem AIB (Tabela 3).

Ayuso et al. (1996) descreveram que a resposta da utilização dessas substâncias em relação à parte aérea é dependente de mais variáveis, como a espécie vegetal, a variedade da planta, a matéria prima utilizada para extrair as substâncias húmicas e a sua origem, os grupos funcionais presentes nas substâncias húmicas e sua reatividade.

Para a massa de matéria fresca das raízes não houve diferença significativa entre os tratamentos (Tabela 3). Em outro experimento, Marino et al. (2008), analisando o conteúdo mineral e respiração das raízes in vitro de Kiwis (Actinidia deliciosa) tratados com substâncias húmicas verificaram a maior massa fresca das raízes, quando aplicaram $10 \mathrm{mg} \mathrm{L}^{-1}$. Por outro lado, Silva et al. (2015) observaram que em Cattleya warneri a adição de ácidos húmicos no meio de cultura proporcionou um incremento de 81 e 159 \% em relação ao controle, para a massa fresca das folhas e das raízes, respectivamente.

Verificou-se que a maior média da massa da matéria seca da parte aérea foi obtida pelo tratamento com o uso de AIB no meio de cultura para concentração de $3 \mathrm{mg} \mathrm{L}^{-1}$ de substâncias húmicas $(0,09 \mathrm{~g})$, não diferindo do tratamento sem o uso de AIB (Tabela 3). Houve diferença significativa somente nas concentrações de 1 e $2 \mathrm{mg} \mathrm{L}^{-1}$, em que o tratamento sem o uso de AIB obteve as maiores massas, ambas com 0,05 g (Tabela 3).

Quanto à massa de matéria seca das raízes, as maiores médias foram obtidas no tratamento sem o uso de AIB, para as concentrações 1,2 e $3 \mathrm{mg} \mathrm{L}^{-1}$ de substâncias húmicas, diferindo estatisticamente do uso de 1 e $2 \mathrm{mg} \mathrm{L}^{-1}$ de tal substância no tratamento com o uso de AIB. Contudo, sem o uso de substâncias húmicas os tratamentos com ou sem AIB não diferiram entre si (Tabela 3). 
Para esta variável, verificando as concentrações de substâncias húmicas com a utilização ou não de AIB, a maior média foi verificada quando utilizada $3 \mathrm{mg} \mathrm{L}^{-1}$ de substância húmica para o tratamento sem o uso de AIB, não diferindo estatisticamente das concentrações 1 e $2 \mathrm{mg} \mathrm{L}^{-1}$ de substâncias húmicas (Tabela 3).

De acordo com Tavares et al. (1995), o maior número, comprimento e massa seca de raízes favorecem o desenvolvimento das plantas e, consequentemente, a qualidade das mudas formadas.

Em experimento realizado por Baldotto et al. (2014), no qual foi avaliado o crescimento de orquídea Cymbidium sp. in vitro em resposta à aplicação de ácidos húmicos, os autores perceberam aumento da massa seca da raiz e da parte aérea das plântulas com aplicações de ácidos húmicos extraídos da compostagem de cama de frango e de esterco bovino, com incrementos em relação ao controle de 21 e $28 \%$, respectivamente.

Diante do exposto, de forma geral, o efeito das substâncias húmicas é variável em função do genótipo. Outro ponto importante é que existem substâncias húmicas oriundas de diferentes origens e assim, a composição do produto poderá levar a resultados distintos na mesma cultura.

No presente estudo, de modo geral, verifica-se que a utilização de substâncias húmicas no meio de cultura é promissora no enraizamento in vitro de mirtileiro 'Woodard', não sendo necessária a aplicação do regulador de crescimento AIB. Além disso, a menor concentração de substâncias húmicas aplicada promoveu incremento no crescimento da parte aérea e do sistema radicular. Esses dois fatos podem resultar na redução dos custos de produção das mudas por micropropagação.

\section{Conclusão}

O enraizamento in vitro de mirtileiro 'Woodard' pode ser realizado com o uso de $3 \mathrm{mg} \mathrm{L}^{-1}$ de substâncias húmicas, sem o ácido indolbutírico.

Os resultados do presente estudo demonstram que o uso de substâncias húmicas são uma alternativa para a micropropagação de mirtileiro, abrindo espaço para que novos trabalhos sejam realizados a fim de confirmar os efeitos que estas substâncias podem proporcionar, quando utilizadas em substituição ou associada a outros reguladores de crescimento. Além disso, os efeitos das substâncias húmicas podem variar em função da fonte de extração das mesmas, da concentração utilizada, do genótipo a ser testado, entre outros fatores. Portanto, é importante estudos com produtos de diferentes origens, assim como o teste com outras concentrações do bioestimulante.

\section{Agradecimentos}

À Coordenação de Aperfeiçoamento de Pessoal de Nível Superior (CAPES) e ao Conselho Nacional de Desenvolvimento Científico e Tecnológico $(\mathrm{CNPq})$, pela concessão das bolsas de estudo e apoio financeiro à pesquisa.

\section{Referências}

Ayuso, M., Hernandez, T., Garcia, C. \& Pascual, J. A. (1996). Stimulation of barley growth and nutrient absorption by humic substances originating from various organic materials. Bioresource and Technology, 57, 251-257.

Baldotto, L. E. B., Baldotto, M. A., Giro, V. B., Canellas, L. P., Olivares, F. L. \& Bressan-Smith, R. (2009). Desempenho do abacaxizeiro 'Vitória' em resposta à aplicação de ácidos húmicos durante a aclimatação. Revista Brasileira de Ciência do Solo, 33(4), 979-990.

Baldotto, L. E. B., Baldotto, M. A., Gontijo, J. B., De Oliveira, F. M., \& Gonçalves, J. (2014). Aclimatização de orquídea (Cymbidium sp.) em resposta à aplicação de ácidos húmicos. Ciência Rural, 44(5), 830-833.

Baldotto, L. E. B., Baldotto, M. A., Soares, R. R., Martinez, H. E. P. \& Venegas, V. H. A. (2012.) Adventitious rooting in cuttings of croton and hibiscus in response to indolbutyric acid and humic acid. Revista Ceres, 59, 476-483.

Baldotto, M. A. \& Baldotto, L. E. B. (2014). Ácidos húmicos. Revista Ceres, 61, 856-881.

Baldotto, M. A., Muniz, R. C., Baldotto, L. E. B. \& Dobbss, L. B. (2011). Root growth of Arabidopsis thaliana treated with humic acids isolated from typical soils of Rio de Janeiro state, Brazil. Revista Ceres, 58, 504-511. 
Baraldi, R., Malavasi, F. F. F., Predieri, S. \& Castagneto, M. (1991). Effect of potassium humate on apple cv. 'Golden Delicious' cultured in vitro. Plant cell, tissue and organ culture, 24(.3), 187-191.

Bednarek, R., Dziadowiec, H., Pokojska, U. \& Prusinkiewicz, Z. (2004). Ecopedological studies. Polish Scientific Publisher PWN, Warsaw (in Polish). 344p.

Bowling, B.L. (2000). The berry grower's companion. Timber Press. 284p.

Camargo, Samila Silva. (2015). Aspectos propagativos de espécies frutíferas com atividade antioxidante: romãzeira e mirtileiro. Dissertação (Mestrado em Agronomia) - Faculdade de Agronomia Eliseu Maciel, Universidade Federal de Pelotas, Pelotas, 103p.

Canellas, L. P., Santos, G. A., Moraes, A. A., Rumjanek, V. M. \& Olivares, F. L. (2000). Avaliação de características de ácidos húmicos de resíduos de origem urbana: I. Métodos espectroscópicos (UV-Vis, IV, RMN 13C-CP/ MAS) e microscopia eletrônica de varredura. Revista Brasileira de Ciência do Solo, 24,741750.

Canellas, L. P., Façanha, A. O., Façanha, A. R. \& Olivares, F. L. (2002). Humic acids isolated from earthworm induces root mitotic sites and plasma membrane H+- ATPase. Plant Physiology, 30, 1951-1957.

Canellas, L. P., Spaccini, R., Piccolo, A., Dobbss, L.B., Okorokova-Facanha, A., Santos, G.A., Olivares, F. L. \& Facanha, A. R. (2009). Relationships between chemical characteristics and root growth promotion of humic acids isolated from Brazilian Oxisols. Soil Science, 174, 611-620.

Carvalho Junior, W. G. O., Melo, M. T. P. De \& Martins, E. R. (2009). Comprimento da estaca no desenvolvimento de mudas de alecrim-pimenta. Ciência Rural, 39(7), 2199-2202.

Costa, F. D. S., Pasqual, M., Pereira, J. E. S., Rodrigues, F. A. \& Miyata, L. Y. (2008). Relação entre o tempo de enraizamento in vitro e o crescimento de plantas de bananeira na aclimatização. Revista Brasileira de Fruticultura, 30(1), 31-37.

Costa, F. H. S., Pereira, M. A. A., Oliveira, J. P. \& Pereira, J. E. S. (2007). Efeito de agentes geleificantes alternativos no meio de cultura no cultivo in vitro de abacaxizeiro e bananeira. Ciência Agrotécnica, 31 (1), 41-46.

Cruz, Jéssica Gonsalez. (2017). Qualidade de luz na micropropagação de mirtileiro 'Woodard'. Dissertação (Mestrado em Agronomia) - Faculdade de Agronomia Eliseu Maciel, Universidade Federal de Pelotas, Pelotas, 65p.

Damiani, C. R., \& Schuch, M. W. (2009). Diferentes substratos e ambientes no enraizamento in vitro de mirtilo. Ciência Rural, 39(2), 563-566.

Damiani, C. R., \& Schuch, M.W. (2008). Multiplicação foto autotrófica de mirtilo através do uso de luz natural. Revista Brasileira de Fruticultura, 30(2), 482487.

Elena, A., Diane, L., Eva, B., Marta, F., Roberto, B., Zamarreño, A. M. \& García-Mina, J. G. (2009) The root application of a purified leonardite humic acid modifies the transcriptional regulation of the main physiological root responses to Fe deficiency in Fe-sufficient cucumber plants. Plant Physiology and Biochemistry, 47, 215-223.

Fracaro, A. A. \& Pereira, F. M. (2004). Distribuição do sistema radicular da goiabeira 'Rica' produzida a partir de estaquia herbácea. Revista Brasileira de Fruticultura, 26(1), 183-185.

Grattapaglia, D. \& Machado, M. A. (1998). Micropropagação. In: Torres, A. C., Caldas, L. S., Buso, J. A. Cultura de tecidos e transformação genética de plantas. Embrapa-SPI: Embrapa-CNPH. 1, 183-260p.

Hartmann, H. T., Kester, D. E., Davies, F. T. \& Geneve, R. L. (1997). Plant propagation: principles and practices. (6a ed.), Prentice Hall, 549-622p.

Kramer, P. J., \& Kozlowski, I. T. (1972). Fisiologia das árvores. Caloute. Gulbenkian, 745 p.

Krikorian, A. D. (1991). Medios de cultivo: generalidades, composición y preparación. In: Roca, W. R., Mroginski, L. A. Cultivo de tejidos en la agricultura: fundamentos y aplicaciones. Cali, Colombia: Centro Internacional de Agricultura Tropical, 41-78p.

Loss, A., Teixeira, M. B., Santos, T. J., Gomes, V. M. \& Queiroz, L. H. (2009). Indução do enraizamento em estacas de Malvaviscus arboreus com diferentes concentrações de ácido indol-butírico (AIB). Acta Scientiarum Agronomy, 31, 269-273.

Loyd, G., \& Mccown, B. (1980). Commercially-feasible micropropagation of mountain laurel, Kalmia latifolia, by use of shoot-tip culture. International Plant Propagation Society Proceedings, 30, 421-427.

Marino, G., Francioso, O., Carletti, P., Nardi, S.\& Gessa, C. (2008) Mineral content and root respiration of in vitro grown kiwifruit plantlets treated with two humic fractions. Journal of plant nutrition, 31(6), 1074-1090.

Murashige, T., \& Skoog, F. (1962). A revised medium for rapid growth and bioassays with tobacco tissue cultures. Physiologia Plantarum, 5, $473-497$.

Pizzatto, M., Wagner Júnior, A., Luckmann, D., Pirola, K., Cassol, D. A. \& Mazaro, S. M. (2011). Influência do uso do AIB, época de coleta e tamanho de estaca na propagação vegetativa de hibisco por estaquia. Revista Ceres, 58, 4877-4892.

Radünz, A. L., Acunha, T. D. S., Giovanaz, M. A., Herter, F. G. \& Chaves, F. C. (2014). Intensidade de poda na produção e na qualidade dos frutos de mirtileiro. Revista Brasileira de Fruticultura, 36 (1), 186-191.

Ristow, N. C., Antunes, L. E. C., Schuch, M. W. \& Trevisan, R. (2009) Crescimento de plantas de mirtilo a partir de mudas micropropagadas. Revista Brasileira de Fruticultura, 31 (1), 210-215.

Rodrigues, L. U., Silva, R. R. Da, Freitas, G. A. De, Santos, A. C. M. Dos \& Tavares, R. De. C. (2018). Ácidos húmicos no desenvolvimento inicial de alface. Pesquisa Aplicada \& Agrotecnologia, 11(2), 101-109. 
Research, Society and Development, v. 10, n. 11, e420101119735, 2021

(CC BY 4.0) | ISSN 2525-3409 | DOI: http://dx.doi.org/10.33448/rsd-v10i11.19735

Rzepka-Plevnes, D., Kulpa, D., Gołębiowska, D.\& Porwolik, D. (2011). Effects of auxins and humic acids on in vitro rooting of strawberry (Fragaria x ananassa Duch.). Journal of Food, Agriculture \& Environment, 9 (3- 4), 592-595.

Schuch, M. W., Tomaz, Z. F. P. (2019). Avanços na propagação do mirtilo vegetativo. Revista Brasileira de Fruticultura, 41(1).

Silva, A. L., Rogalski, M., Moraes, L. K. A., Feslibino, C., Crestani L. \& Guerra, M. P. (2003). Estabelecimento e multiplicação in vitro de porta-enxertos de Prunus. Revista Brasileira de Fruticultura, 25(2), 297-300.

Silva, M. A. C., Santos, W. O., Simoura, N. T., Tesch, J. A., Ruas, K. F., Colodete, C. M., Tannure, F. P., Barbirato, J. O., Ramos, A. C. \& Dobbs, L. B. (2015). Ácidos húmicos de vermicomposto estimulam o crescimento in vitro de plântulas de Cattleya warnieri (Orchidaceae). Rodriguésia, 66 (3), $759-768$.

Souza, A. L. K., Schuch, M. W., Antunes, L. E. C., Schmitz, J. D., Pasa, M. S., Camargo, S. S.\& Carra, B. (2011). Desempenho de mudas de mirtilo obtidas por micropropagação ou estaquia. Pesquisa Agropecuária Brasileira, 46, 868-874.

Souza, A. S. \& Junghans, T. G. (2006). Introdução à micropropagação de plantas. Cruz das Almas: Embrapa Mandioca e Fruticultura Tropical, 152p.

Tahiri, A., Destain, J., Thonart, Ph., Ongena, M. \& Druart, Ph. (2016). Comparison of explant responses treated with leachate and leonardite sources of humic substances during in vitrorootingof woody plants. Communications in agricultural and applied biological sciences, Gante, 81(1), 158-165.

Taiz, L., \& Zeiger, E. (2004). Fisiologia vegetal. Porto Alegre: Artmed, 719 p.

Tavares, M. S. W., Kersten, E. \& Siewerdt, F. (1995) Efeitos do ácido indolbutírico e da época de coleta no enraizamento de estacas de goiabeira (Psidium guajava L.). Scientia Agricola, 52 (2), 310-317.

Trevisan, S., Botton, A., Vaccaro, S., Vezzaro, A., Quaggiotti, S.\& Nardi, S. (2011). Humic substances affect Arabidopsis physiology by altering the expression of genes involved in primary metabolism, growth and development. Environmental and Experimental Botany, 74, 45-55.

Vaughan, D., Malcolm, R. E. \& Ord, B. G. (1985). Influence of humic substances on growth and physiological process. In: Vaughan, D. \& Malcolm, R.E., eds. Soil organic matter and biological activity. Dordrecht, Kluwer Academic Publishers, 77-108.

Zandonadi, D. B., Canellas, L. P. \& Façanha, A. R. (2007). Indolacetic and humic acids induce lateral root development through a concerted plasmalemma and tonoplast $\mathrm{H}^{+}$pumps activation. Planta, 225, 1583-1595.

Zietemann, C.\& Roberto, S. R. (2007). Efeito de diferentes substratos e épocas de coleta no enraizamento de estacas herbáceas de goiabeira, cvs. paluma e século XXI. Revista Brasileira de Fruticultura, 29 (1), 31-36. 